Research Article

\title{
Spousal Dementia Grief: A Research Report from the Two-Track Model of Dementia Grief Project
}

Alexander Manevich ${ }^{1}$, Simon Shimshon Rubin 1, 2, ${ }^{*}$, Rachel Ben-Hayun ${ }^{3}$, Judith Aharon-Peretz ${ }^{3}$, Michael Katz ${ }^{1}$

1. International Laboratory for the Study of Loss, Bereavement and Human Resilience and the School of Psychological Sciences, University of Haifa, Haifa, Israel; E-Mails: ManevichAlex7@gmail.com; rubin@psy.haifa.ac.il; mkatz@psy.haifa.ac.il

2. Department of Psychology, Max Stern Yezreel Valley College, Israel

3. Cognitive Neurology Institute, Rambam Health Care Campus, Haifa, Israel; E-Mails: jaharon@rambam.health.gov.il; $\underline{r \text { hayun@rambam.health.gov.il }}$

* Correspondence: Simon Shimshon Rubin; E-Mail: rubin@psy.haifa.ac.il

Academic Editor: Ladislav Volicer

Special Issue: Advanced Dementia: Enjoy It or Avoid It?

OBM Geriatrics

2021, volume 5, issue 1

doi:10.21926/obm.geriatr.2101160
Received: September 07, 2020

Accepted: February 20, 2021

Published: March 12, 2021

\begin{abstract}
Caregiving for a loved one suffering from cognitive decline involves coping with many challenges and losses. This experience increases the risk of worsening the physical and mental health of the caregiver and has been the subject of a substantial number of studies focusing on the stress and burden of the primary caretaker. Theory and research on the grief reactions experienced by the family members, however, continues to lag in terms of the attention given to the behavioral and psychological burden of caregivers. This study aimed for a deeper understanding of the emotional processes in an individual involved in caring and caregiving for a spouse suffering from cognitive decline, through the prism of the Two-Track Model of Dementia Grief (TTM-DG). The TTM-DG
\end{abstract}

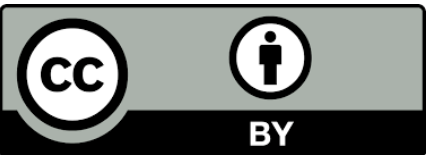

(C) 2021 by the author. This is an open access article distributed under the conditions of the Creative Commons by Attribution License, which permits unrestricted use, distribution, and reproduction in any medium or format, provided the original work is correctly cited. 
emphasizes the continuous emotional attachment to the loved one suffering from cognitive decline (Track II), along with a medico-psychiatric perspective associated with stress, trauma, and changes in life (Track I). In this research project, we examined the degree to which spouses of cognitively impaired, deceased, and healthy partners showed differences and perceptible patterns considering the elements associated with the model and their interrelationship. These elements include behavioral characteristics of the clinical patients suffering from cognitive decline, objective circumstances of the caregiving situation, personality measures of attachment of the caring spouse, and a range of measures assessing psychological well-being and spousal relationship. The current study is a part of a larger ongoing project in Israel to address loss and grief among caregiving family members whose loved ones suffer from cognitive decline. The findings reported in the current paper are based on data derived from self-report questionnaires (i.e., socio-demographic variables, problematic behaviors in patients, objective burden, social support, physical health status, attachment patterns, depression, dementia grief, and relationship satisfaction). Participants in the sample size of 49 came from three groups: (a) spouses of patients suffering from cognitive decline, (b) widowers of deceased dementia sufferers, (c) and a control group of similarly aged participants whose spouses have no cognitive or functional impairment. Examination of the research hypotheses was done by running correlations and one/two-way analyses of variance (ANOVA). Behavioral disorders in the affected spouse correlated positively with the objective burden of the caring/caregiving spouse and with outcome variables. That is, biopsychosocial functioning (Track I) and the ongoing attachment bond with the ill spouse (Track II); objective burden correlated positively with depression and dementia grief, but not with relationship satisfaction; poor caregiver's physical health was associated positively with depression and dementia grief, but not with relationship satisfaction; social support correlated positively with low levels of depression and dementia grief, as well as to the higher degree of relationship satisfaction; insecure attachment was found to correlate positively with depression and dementia grief, but not with relationship satisfaction. Spouses of cognitively impaired patients reported more difficulties in outcome variables compared to the control group; widowers of deceased dementia sufferers reported higher levels of dementia grief and depression than the control group. In terms of outcome measures, there was no difference between widowers and spouses of cognitively impaired patients. Among the control group participants, there was no difference between secure and insecure attachment on outcome variables. A significant difference between secure and insecure attachment on outcome variables was observed among spouses of cognitively impaired patients and widowers so that insecure participants reported higher levels of distress. The findings of the present study constitute the initial empirical evidence for the utility of the TTM-DG and support the transition of the field of loss and bereavement, which emphasizes the importance of the emotional attachment with the loved one as one of the primary foci of the process of coping with the loss. Furthermore, the findings highlight factors that contribute to the health and emotional resilience (secure attachment style, perceived social support, etc.) and provide a framework that can assist in the process of clinical assessment and intervention to improve the quality of life of caregivers whose loved one suffers from cognitive decline. 


\section{Keywords}

Two-Track Model of Dementia Grief (TTM-DG); Two-Track Model of Bereavement; attachment; continuing bonds; dementia caregiving; spousal dementia grief; non-death loss

\section{Introduction}

Age-related illnesses are one of the major health and welfare challenges faced by society today. Dementia, especially Alzheimer's disease, is considered to be among the most painful and devastating diseases of old age. They have profound effects on the patients as well as upon their family members and society as a whole. Dementia (major neurocognitive disorder) is a general name that includes a variety of syndromes diagnosed on the basis of two main criteria: (a) significant cognitive decline from a previous level of performance in one or more of the cognitive domains, including complex attention, executive function, learning, and memory, language, perceptual-motor, or social cognition; and (b) the cognitive deficits interfere with independence in everyday activities [1]. These syndromes have diverse clinical characteristics and etiologies, including inter alia, cerebrovascular disease, Lewy body disease, frontotemporal degeneration, traumatic brain injury, and Alzheimer's disease [2].

In more than half of the diagnosed cases, the main cause of dementia is Alzheimer's disease. It is estimated to affect nearly 20 percent of the older Jewish [3] and Arab [4] population in Israel and is the fifth leading cause of death among adults aged 65 and over in the US [5]. With the aging of the population, it is estimated that compared to 2010, the number of diagnosed Alzheimer's cases in the US will triple over the following forty years [6]. This dramatic increase will add to the burden on the country's care systems and on the health system in general, particularly upon informal patient support networks, mostly including spouses and adult children-who provide a significant portion of the daily care needed in dementia patients [7].

Cumulative evidence highlights the stress associated with caregiving for a person suffering from cognitive decline. This situation increases vulnerability to health deficiencies [8-10]. These include, inter alia, the decline in sleep quality [11] and immune system functioning [12], and high levels of depression and anxiety [13]. There are several reports describing the stress and burden associated with the role of the primary caretaker, while the scope of research on grief reactions experienced by the caring and caregiving family members has been relatively limited until the last two decades [14].

Pre-death grief in the context of dementia caregiving (i.e., dementia grief) [15] is a universal phenomenon whose expressions may vary from one culture to another [16-18]. This specific grief is defined as the caregiver's emotional and physical response to the dementia-related losses in a meaningful care recipient. This response is due to (a) the patient's psychological death, which is asynchronous with his or her physical death, (b) the lengthy and ambiguous course of the disease, (c) impaired communication between the care recipient and family members, (d) changes in relationship quality, family roles and caretaker's lack of freedom. Pre-death grief may contribute to highly distressing feelings of depression, burden, and maladaptive coping and adjustment [19]. 
Empirical research documenting the trajectory of dementia grief among caregiving family members is growing rapidly and highlights that grief-related reactions are evident in family members. These begin with the initial changes in cognitive functions of a dementia patient and increase with the progression of the disease [20-22]. Despite these developments, the understanding of the care and the effects of caregiving on family members after the death of the patient is still rather limited [23]. Evidently, while the caregivers may experience the care-recipient's death as a relief [24], they still face additional challenges in their grieving that may last well beyond the first year of bereavement [25].

Approximately 20 percent of bereaved family caregivers of dementia patients would qualify for classification of complicated grief [26], or for Prolonged Grief Disorder (PGD) [27], and Persistent Complex Bereavement Disorder (PCBD) [1]. (For an overview of the differences and similarities between PGD and PCBD, please see: [28]). Furthermore, high levels of grief reactions prior to a person's expected death are a significant risk factor for distress and adjustment difficulties during the bereavement period that may require professional intervention [29].

Despite the increase in the number of studies on dementia grief, the knowledge in this field thus far continues to suffer from limitations [30], including lack of control groups, use of non-validated and comparative measurements, a dearth of studies conducted during the bereavement period, and a lack of cultural, ethnic and gender diversity. Besides the need for theory-driven and theory-informed research drawing from the knowledge base arising from interpersonal attachment, a significant contribution is made by loss and bereavement $[31,32]$ to the evolution of the field. The present study reflects our attempt to build upon and integrate insights from these studies to explore the experience of the caregiving spouse of a patient with dementia.

Attachment theory is one of the main theories that attempt to explain the nature of interpersonal relationships [33-35]. This theory emphasizes the importance of relationships in the development and socio-emotional functioning throughout the life of the individual [36]. The attachment style of the individual may significantly impact their emotional adjustment throughout the grief and mourning process [37]. Compared to those with secure attachment, those without it may be at higher risk for coping difficulties [38]. Therefore, attachment style should be considered when formulating professional intervention [39]. Surprisingly, the attention to dementia caregiving based on the attachment theory insights is rarely reported [40]. Nonetheless, empirical evidence is beginning to accumulate in this area. For example, a secure attachment was associated with the positive well-being of the caregiver and with an increase in the ability to provide support and care to others [41].

The Two-Track Model of Dementia Grief (TTM-DG), described by Rubin, Manevich, and Doron [42], builds on a well-established paradigm (i.e., The Two-Track Model of Bereavement; [43-45]) that has proven to be effective over the years in directing research attention and formulating clinical interventions in interpersonal losses [31, 32, 46-52]. The TTM-DG emphasizes the ongoing emotional attachment to a loved one suffering from cognitive decline, along with a medico-psychiatric perspective associated with stress, trauma, and change in life [42]. This comprehensive model integrates current knowledge and provides an adequate solution to the limitations of prior models concerning dementia grief $[15,53,54]$ by using bifocal attention given to the biopsychosocial aspects of the caregiving role alongside the interpersonal sphere. Thus, theoretical research and clinical lenses enlarge the 
consequences of caring and caregiving for a loved one who suffers from cognitive decline throughout the course of the disease, as well as during the bereavement period.

The four categories of TTM-DG that describe the requirements for coping with a family member suffering from cognitive decline and its implications on caring/caregiving family members (CCFM) are: (a) attributes of the family member suffering from cognitive decline, which includes medical diagnosis, severity (or alternatively, bereavement period and time that elapsed since patient's death), and a particular pattern of physical and neuropsychiatric symptomatology, (b) objective circumstances of caring/caregiving (requirements, overall losses, and losses vis a vis the impaired family member), (c) characteristics and resources of the CCFM that include background factors, context and psychological resources as a moderating factor, (d) and a conceptual and practical assessment of dementia grief responses of the CCFM across two multidimensional and interrelated tracks.

Track I addressed caregiving for dementia as a potentially traumatic and chronic experience with physical (changes in appetite, sleep, and sexual drive), psychological (anxiety, depression, self-esteem, etc.), and social (family, friends, colleagues, and so on) implications. On the other hand, Track II referred to the fracture that may occur in the ongoing relational bond with the patient and the ability to reconstruct and integrate the 'illness/death story' into the personal narrative. The reactions related to this track may refer to yearning and longing for the patient as he or she was before the illness, the extent of disorganized trauma-like experiences focused on the personhood of the ill family member, predominance of relevant cognitions related to loss and emotions reflecting aspects of shock and numbness, heightened search for cues related to the person, the degree of psychological disorganization, and the extent of re-organization achieved (see Figure 1). 
OBM Geriatrics 2021; 5(1), doi:10.21926/obm.geriatr.2101160

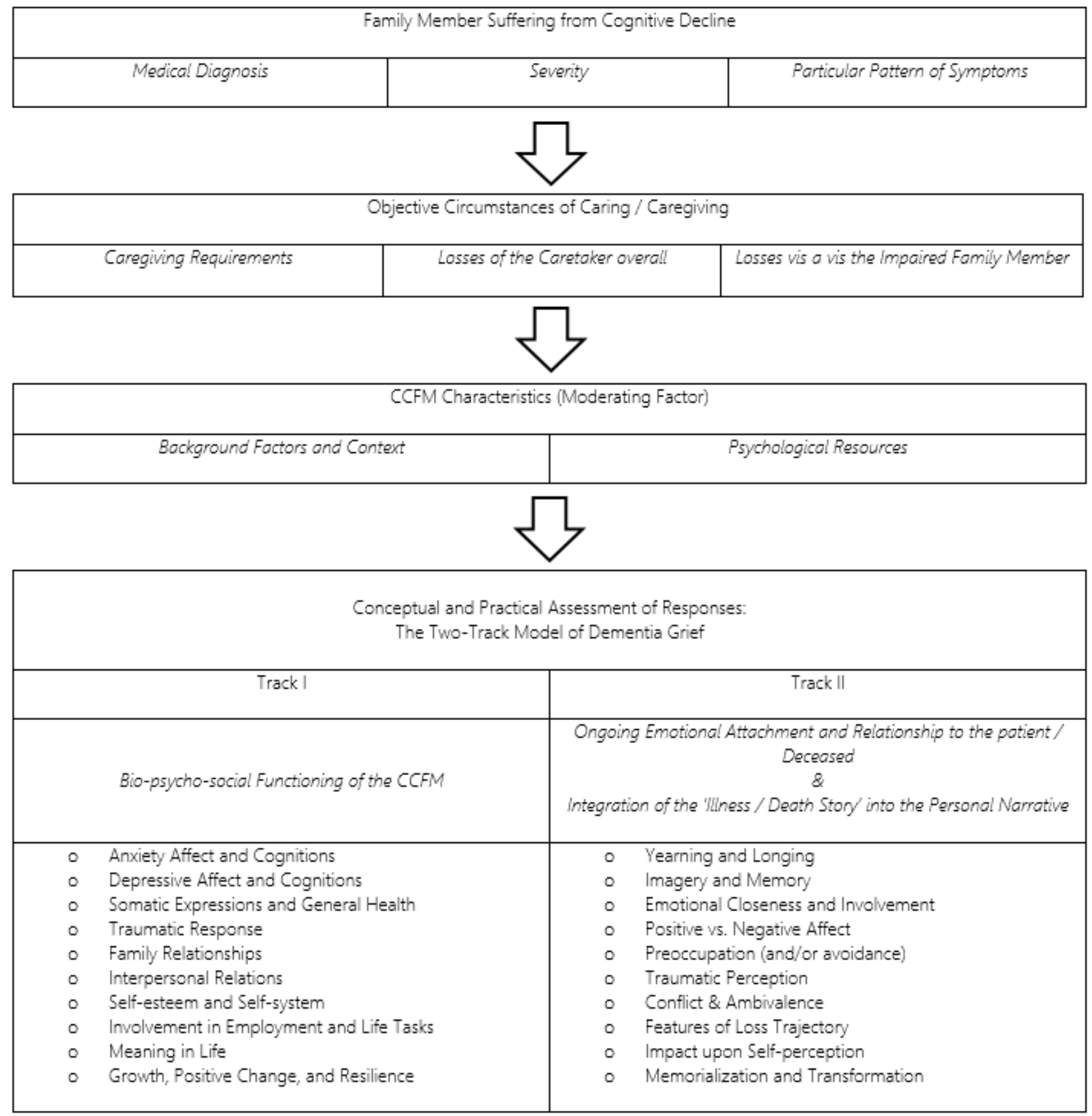
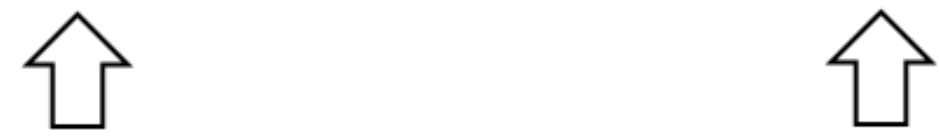

- During the assessment process, the intensity, duration, frequency, and characteristics that trigger or assist in alleviating these reactions should be taken into consideration, and accordingly, whether and where to intervene.

Figure 1 Dimensions of Patient and Caring/Caregiving Family Member (CCFM) Relevant for Assessment (reprinted with permission from [42]). 


\section{Research Objectives}

The present study aimed to enhance the understanding of the emotional processes involved in caring and caregiving for a spouse suffering from cognitive decline, using the prism of the Two-Track Model of Dementia Grief. A heightened understanding of the issue will help promote evidence-based evaluation and intervention methods to improve the quality of life of family members who care for a loved one suffering from cognitive decline.

\section{Hypotheses}

(1) Patient's characteristics and caregiving requirements: (1.a) a positive correlation between behavioral disorders (agitation, irritability, suspicion, etc.) of the affected spouse with the objective burden (e.g., personal freedom of the caregiver, health, and engagement in social activities) and outcome variables on both tracks of the proposed model (i.e., depression, grief, and relationship satisfaction). That is, greater distress on overall biopsychosocial functioning (Track I) and the ongoing emotional bond with the ill spouse (Track II); (1.b) a positive correlation between objective burden levels and outcome variables.

(2) Caring/caregiving spouse characteristics: (2.a) caregiver's poor physical health will positively correlate with outcome variables; (2.b) The association between lack of social support and distress on outcome variables; (2.c) insecure attachment style correlates with higher levels of distress on outcome variables.

(3) Between-groups differences: (3.a) spouses of cognitively impaired patients will exhibit more difficulties on outcome variables compared to the control group, (3.b) spouses of deceased dementia patients will exhibit more difficulties on outcome variables in compared to the control group, (3.c) spouses of deceased dementia patients will exhibit lower levels of distress in comparison to spouses of cognitively impaired patients.

(4) Attachment $X$ Groups interaction effect: a significant difference between secure and insecure attachment on outcome variables among spouses of cognitively impaired patients and widowers, so that insecure participants will report higher levels of distress.

\section{Method}

\subsection{Design and Participants}

To examine the research hypotheses, the study was designed to be cross-sectional and included three groups: spouses of people currently suffering from cognitive decline, widows and widowers of deceased dementia sufferers, and a control group of participants whose spouses are without cognitive or functional impairment. All the participants in the current research were Israeli Jewish. The caring/caregiving group included spouses of patients suffering from cognitive impairment with varying degrees of severity, and 94 percent of patients were diagnosed with dementia (for more details on the medical diagnoses, please see: Appendix 1). The demographic characteristics of the study participants are presented in Table 1. 
Table 1 The distribution of demographic variables by groups.

\begin{tabular}{|c|c|c|c|}
\hline & Control & $\begin{array}{l}\text { Cognitive } \\
\text { Impairment }\end{array}$ & Widowers \\
\hline $\begin{array}{l}\text { No. of Participants } \\
(\mathrm{N}=49)\end{array}$ & 27 & 17 & 5 \\
\hline No. of Women & 17 & 10 & 4 \\
\hline (\%) & $(63 \%)$ & $(58.8 \%)$ & $(80 \%)$ \\
\hline Mean Age & 73.15 & 73.5 & 76 \\
\hline (S.D.) & (9.89) & $(7.23)$ & $(7.62)$ \\
\hline $\begin{array}{l}\text { Age } \\
\text { (Range) }\end{array}$ & $55-89.5$ & $62-89$ & $66-85$ \\
\hline Y. of Education & 15.07 & 15.35 & 14.2 \\
\hline (S.D.) & (3.8) & $(3.87)$ & (3.35) \\
\hline Y. of relationship & 46.41 & 45.59 & 44.8 \\
\hline (S.D.) & (15.73) & $(13.52)$ & (13.63) \\
\hline SES* & 2 & 2.18 & 2.2 \\
\hline (S.D.) & (.73) & (.64) & (1.3) \\
\hline Religiosity* & 3.92 & 4.37 & 4.56 \\
\hline (S.D.) & $(1.04)$ & (.98) & $(.72)$ \\
\hline \multicolumn{4}{|l|}{ Months Since } \\
\hline $\begin{array}{l}\text { Diagnosis/Bereavement } \\
\text { (Range) }\end{array}$ & - & $1-216$ & $3-156$ \\
\hline \multicolumn{4}{|l|}{ Questionnaire } \\
\hline Administration & 13 - Hard copy & 14 - Hard copy & 2 - Hard copy \\
\hline (No. of participants) & 14 - Online & 3 - Online & 3 - Online \\
\hline \multicolumn{4}{|l|}{ Questionnaire } \\
\hline Administration & 24 - Ind. & 14 - Ind. & 4 - Ind. \\
\hline (No. of participants) & $3-S M$ & $3-S M$ & $1-S M$ \\
\hline
\end{tabular}

* High score = low level; Ind. = independently; SM = with a staff member assistance

\subsection{Measures}

\subsubsection{Family Member Suffering from Cognitive Decline}

Problematic Behavior Inventory (PBI): This questionnaire measures the range and degree of problematic behaviors in Alzheimer's patients [55]. Healthy respondents evaluate patient behaviors in terms of 14 items. The range of each item on a Likert scale is from 1 to 4 . Higher scores indicate a greater level of problematic behaviors. The internal consistency in the current study was high $(\alpha=0.90)$. 


\subsubsection{Objective Circumstances of Caring/Caregiving}

Objective Burden Inventory $(O B \mid)$ : The questionnaire measures the self-rated objective burden related to the caregiving features of the spouse of the patient and their perceived impact [56]. Participants indicate the degree to which the caregiver role has affected their lives on the basis of nine items. The range of each item on a Likert scale was from 1 to 5 . Higher scores indicated a greater level of caregiving burden $(\alpha=0.81)$.

\subsubsection{Characteristics of Caring/Caregiving Spouse}

Socio-demographic Questionnaire: This questionnaire addresses a broad range of relevant variables in addition to gender, ethnicity, age, level of education, religiosity, and socio-economic status. Medical Outcomes of Study Social Support Survey: This self-report questionnaire assesses social support [57] and consists of 19 items rated on a five-point 'Likert' scale. Higher scores indicate greater social support $(\alpha=0.87)$. Experiences in Close Relationships Scale (ECR-S): This short version [58] has 12 items addressing the two basic dimensions of attachment patterns: anxiety and avoidance. Questionnaire items are designed as statements that describe patterns of emotions, behaviors, and cognition in close relationships and are rated on a Likert scale from 1 to 7 . Higher scores indicate a greater level of attachment anxiety and avoidance $(\alpha=0.81)$. Physical Health Questionnaire: This self-report questionnaire assesses the physical health status [59] of the spouse of the dementia patient and consists of 9 items and is rated on a Likert scale from 1 to 3 . High scores indicate poor physical health $(\alpha=0.85)$.

\subsubsection{A Two-track Assessment of Dementia Grief Responses}

Center for Epidemiological Studies Depression Scale (CES-D-10): The original questionnaire [60] was developed to assess depression in the population. The short version of this questionnaire [61] includes ten statements to be answered as "yes" or "no". Higher scores indicate a greater degree of depression $(\alpha=0.79)$. Relationship Assessment Scale: This questionnaire was developed by Hendrick [62] to assess relationship satisfaction between spouses. This questionnaire includes seven items. Each item is rated on a Likert scale from 1 to 5 . Higher scores indicate a greater level of satisfaction. The internal consistency in this study was high $(\alpha=0.903)$. The Two-Track Bereavement Questionnaire for Complicated Grief (TTBQ2-CG31): This is a self-report measure based on the TTM and clinical research to date and aims to assess various aspects of people's responses to the death of a close person over time [63]. The short version of this questionnaire [64] includes 31 items rated on a five-point Likert scale. Higher scores indicate a greater degree of biopsychosocial and relational distress. Internal consistency was found to be high $(\alpha=0.88)$. In this study, three comparable versions of the questionnaire were used: the Two-Track Coping Questionnaire (control group), the Two-Track Dementia Grief Questionnaire (spouses of cognitively impaired patients) and the original Two-Track Bereavement Questionnaire for Complicated Grief (widows and widowers). Figure 2 illustrates the flow of the caregiving experience and the stages to which each of the questionnaires is targeted in this research with the Two-Track Model of Dementia Grief. 
OBM Geriatrics 2021; 5(1), doi:10.21926/obm.geriatr.2101160

\begin{tabular}{|c|c|}
\hline \multicolumn{2}{|c|}{ Family Member Suffering from Cognitive Decline } \\
\hline Research Groups \\
\hline Objective Circumstances of Caring / Caregiving \\
\hline \multicolumn{2}{|c|}{ Objective Burden Inventory } \\
\hline CCFM Characteristics (Moderating Factor) \\
\hline Medical Outcomes Study Social Support Survey \\
\hline \\
\hline
\end{tabular}

Figure 2 Study questionnaires according to the Two-Track Model of Dementia Grief (TTMDG) variables.

\subsection{Procedure}

The current study is part of a broad and ongoing project being conducted at the International Laboratory for the Study of Loss, Bereavement and Human Resilience in collaboration with the Cognitive Neurology Institute at the 'Rambam' Health Care Campus in Israel. This project focused on loss and grief among caring and caregiving family members whose loved ones suffer from cognitive decline. The project was approved by the Helsinki committee at 'Rambam' Health Care Campus (024818-RMB) and at the University of Haifa (444/18), Israel. The participants were recruited by the medical staff at the Cognitive Neurology Institute, as well as through collaboration with geriatric organizations and institutions (such as nursing homes and elderly day-care centers) and the online network. 


\subsection{Statistical Analyses}

A number of statistical analyses were conducted to examine the research hypotheses. Associations between patient's characteristics, caregiving requirements, caring and caregiving spouse characteristics, and outcome variables were examined using correlations and Pearson's significance tests. The differences between the study groups were examined through one-way ANOVA; study groups were considered independent variables, while overall functioning (Track I) and the ongoing emotional bond with the patient indicators (Track II) were used as dependent variables. The interaction effect between groups and attachment variables on outcome measures was examined by using a twoway ANOVA.

\section{Results}

Patient's characteristics and caregiving requirements: (1.a) As can be seen in Table 2, high levels of behavioral disorders correlated positively with high levels of objective burden and depression, and dementia grief, and low levels of relationship satisfaction. (1.b) Objective burden correlated positively with depression and dementia grief. There was no significant correlation between objective burden and relationship satisfaction.

Table 2 The correlation matrix of variables and Pearson's significance tests across the entire sample $(\mathrm{N}=49)$.

\begin{tabular}{|c|c|c|c|c|c|c|c|}
\hline & TTBQ-CG & CES-D & RAS & $\mathrm{PHQ}$ & ECR-S & MOS & $\mathrm{OBI}$ \\
\hline $\mathrm{PBI}$ & $.700 * *$ & $.579 * *$ & $-.577 * *$ & .114 & .233 & -.204 & $.582 * *$ \\
\hline $\mathrm{OBI}$ & $.404^{* *}$ & $.442 * *$ & -.227 & $.375^{* *}$ & -.128 & -.064 & \\
\hline MOS & $-.424 * *$ & $-.437 * *$ & $.395^{* *}$ & -.183 & $-.393 * *$ & & \\
\hline ECR-S & $.328^{*}$ & $.365^{* *}$ & -.147 & .081 & & & \\
\hline $\mathrm{PHQ}$ & $.434 * *$ & $.357^{*}$ & -0.41 & & & & \\
\hline RAS & $-.630 * *$ & $-.506 * *$ & & & & & \\
\hline CES-D & $.706 * *$ & & & & & & \\
\hline
\end{tabular}

Caring/caregiving spouse characteristics: (2.a) According to Table 2, the caregiver's poor physical health exhibits a positive correlation with depression and dementia grief, but not with relationship satisfaction. (2.b) Social support has a positive correlation with low levels of depression and dementia grief, as well as with a higher degree of relationship satisfaction. (2.c) Insecure attachment correlated positively with depression and dementia grief and did not exhibit any significant correlation with relationship satisfaction.

Between-groups differences: Between-groups differences in the background and outcome measures can be seen in Table 3 and Table 4, respectively. 
Table 3 Between-groups differences in background measures.

\begin{tabular}{llllll}
\hline & Control & $\begin{array}{l}\text { Cognitive } \\
\text { Impairment }\end{array}$ & Widowers & One-Way ANOVA & $\begin{array}{l}\text { Partial Eta } \\
\text { Squared }\end{array}$ \\
\hline PBI & 1.14 & 1.87 & - & $F(1,39)=26.217 ; p<.001$ & .402 \\
& $(.16)$ & $(.72)$ & & & \\
OBI & 2.74 & 3.49 & 2.36 & $F(2,46)=8.77 ; p=.001$ & .276 \\
& $(.72)$ & $(.64)$ & $(.37)$ & & \\
MOS & 4.16 & 3.89 & 3.46 & $F(2,46)=2.52 ; p=.09$ & .099 \\
& $(.67)$ & $(.65)$ & $(.84)$ & & \\
PHQ & 1.72 & 1.65 & 1.78 & $F(2,46)=.234 ; n . s$ & .010 \\
& $(.44)$ & $(.34)$ & $(.63)$ & & .030 \\
ECR-S & 2.35 & 2.24 & 2.77 & $F(2,46)=.707 ; n . s$ & \\
\hline
\end{tabular}

Table 4 Between-groups differences in outcome measures.

\begin{tabular}{llllll}
\hline & Control & $\begin{array}{l}\text { Cognitive } \\
\text { Impairment }\end{array}$ & Widowers & One-Way ANOVA & $\begin{array}{c}\text { Partial Eta } \\
\text { Squared }\end{array}$ \\
\hline TTBQ-CG & 2.04 & 2.50 & 2.58 & $\mathrm{~F}(2,46)=6.304 ; \mathrm{p}<.005$ & .215 \\
& $(.33)$ & $(.55)$ & $(.75)$ & & \\
CES-D (Track I) & 1.17 & 1.32 & 1.5 & $\mathrm{~F}(2,46)=5.58 ; \mathrm{p}<.01$ & .195 \\
& $(.16)$ & $(.28)$ & $(.30)$ & & \\
\multirow{2}{*}{ RAS (Track II) } & 4.48 & 3.39 & 3.91 & $\mathrm{~F}(2,44)=8.317 ; \mathrm{p}=.001$ & .274 \\
& $(.59)$ & $(1.13)$ & $(.91)$ & & \\
\hline
\end{tabular}

We will first discuss differences in background variables. According to Table 3, no significant difference was observed between the study groups except for the patient's behavioral problems and the objective burden (Social support had marginal significance; $p=0.09$ ). Post-hoc analyses (Scheffe) were conducted to examine the source of the differences between the groups on the objective burden. There was a significant difference between spouses of cognitively impaired patients to widowers $(p<$ 0.01 ) and the control group ( $p<0.005)$ that the former group reported higher levels of objective burden. There was no significant difference between widowers and the control group.

(3.a) To examine the source of the differences mentioned in Table 4, planned contrasts were conducted. Spouses of cognitively impaired patients reported higher levels of dementia grief $(p<0.005)$ and depression ( $p<0.05)$, as well as lower levels of relationship satisfaction $(p<0.001)$ compared to the control group. (3.b) Planned contrasts revealed higher levels of dementia grief $(p<0.05)$ and depression $(p<0.005)$ among widowers compared to the control group. No significant difference between these two groups was observed in relationship satisfaction (n.s.). (3.c) Planned contrasts 
revealed no significant difference between widowers and spouses of cognitively impaired patients on outcome variables.

Attachment $X$ Groups interaction effect: To divide the participants into two comparable groups, we calculated a median score for the measurement of attachment (2.333). In addition, the sample of widowers was small; therefore, we merged the two clinical groups into one $(n=22)$. The following table displays numerical differences in dementia grief, depression, and relationship satisfaction (Table 5).

Table 5 Moderating effect of attachment $X$ research groups on dementia grief, depression, and relationship satisfaction.

\begin{tabular}{|c|c|c|c|c|}
\hline & $\begin{array}{l}\text { Secure } \\
(n=24)\end{array}$ & & $\begin{array}{l}\text { Insecure } \\
(n=25)\end{array}$ & \\
\hline & Control & Clinical & Control & Clinical \\
\hline \multirow{2}{*}{ TTBQ-CG } & 2.06 & 2.23 & 2.03 & 2.85 \\
\hline & (.31) & $(.54)$ & $(.36)$ & $(.47)$ \\
\hline \multirow{2}{*}{ CES-D (Track I) } & 1.19 & 1.20 & 1.15 & 1.56 \\
\hline & (.19) & $(.24)$ & $(.14)$ & $(.22)$ \\
\hline \multirow{2}{*}{ RAS (Track II) } & 4.42 & 3.69 & 4.53 & 3.33 \\
\hline & $(.72)$ & (1.01) & $(.50)$ & $(1.11)$ \\
\hline
\end{tabular}

(4) To examine the hypothesis, we conducted a two-Way ANOVA with attachment and research groups as independent variables and dementia grief as a dependent variable (Table 5). Significant effects were found for attachment $\left[F(1,45)=5.928, p<0.05\right.$; partial eta squared $\left.\left(\eta_{p}{ }^{2}\right)=0.116\right]$, group $\left[F(1,45)=17.027 ; p<0.001 ; \eta_{p}^{2}=0.275\right]$ and interaction $\left[F(1,45)=7.227 ; p<0.01 ; \eta_{p}^{2}=0.138\right]$. OneWay ANOVA showed no significant difference between the control and the clinical group in terms of dementia grief among securely attached individuals $[F(1,22)=0.983 ; n . s]$. On the other hand, a significant difference was observed among insecurely attached individuals $[F(1,23)=24.428 ; p<0.001$; $\left.\eta_{\mathrm{p}}{ }^{2}=0.515\right]$. In a two-Way ANOVA with attachment and research groups as independent variables and depression as a dependent variable, significant effects were observed for attachment $[F(1,45)=8.285$, $\left.p<0.01 ; \eta_{p}{ }^{2}=0.155\right]$, group $\left[F(1,45)=13.186 ; p<0.005 ; \eta_{p}{ }^{2}=0.227\right]$, and interaction were found as well $\left[F(1,45)=12.761 ; p<0.005 ; \eta_{p}^{2}=0.221\right]$. One-Way ANOVA showed no significant difference between the control and the clinical group considering depression among securely attached individuals $[F(1,22)=0.001 ; n . s]$. However, there was a significant difference among insecurely attached individuals $\left[F(1,23)=31.639 ; p<0.001 ; \eta_{p}^{2}=0.579\right]$. In a two-Way ANOVA with attachment and research groups as independent variables and relationship satisfaction as a dependent variable, the effect was significant for group $\left[F(1,43)=14.523, p<0.001 ; \eta_{p}^{2}=0.252\right]$, but not for attachment $[F(1,43)=0.234$; n.s, $]$, and interaction $[F(1,43)=0.879 ;$ n.s. $]$. 


\section{Discussion}

This study aimed to deepen the understanding of the emotional, cognitive, and behavioral processes involved in caring and caregiving for a spouse suffering from cognitive decline through the prism of the Two-Track Model of Dementia Grief (TTM-DG) [42].

The first part of the hypotheses dealt with the patient's characteristics and caregiving requirements and their relation to outcome measures, that is, biopsychosocial functioning (Track I) and the ongoing attachment bond with the ill spouse (Track II). (1.a) We hypothesized that behavioral disorders in the affected spouse will correlate positively with the objective burden of the caring/caregiving spouse and with outcome variables; this hypothesis was confirmed in this study. A high correlation was observed between the patient's problematic behaviors and dementia grief symptomatology as measured by the TTBQ-CG is $\left(r(49)=0.700 ; p<0.01\right.$; Adjusted $\left.R^{2}=0.476\right)$. This finding corresponds with previous studies, arguing that the primary caregivers cited neuropsychiatric disorders of the patient as one of the most significant distressing factors with which, they must cope (e.g., [22, 65]). (1.b) We also hypothesized a positive correlation between objective burden and outcome variables. Indeed, objective burden correlated positively with depression and dementia grief but not with relationship satisfaction. Therefore, this hypothesis was largely confirmed. This finding is consistent with the extensive documentation of the aversive effects of caregiving burden and the psychological well-being of the caregiver $[66,67]$.

The second hypothesis referred to the correlation between caregiver's characteristics and outcome measures. The caregiver's poor physical health was associated positively with depression and dementia grief, but not with relationship satisfaction. Therefore, hypothesis 2.a was partially confirmed. This finding is consistent with earlier findings assessing the relationship between caregivers' physical health and their mental distress [68]. Social support correlated positively with low levels of depression and dementia grief, as well as to a higher degree of relationship satisfaction. Thus, hypothesis 2.b was confirmed. This finding underscores the importance of a social support network for the mental health of caregivers [69], in particular, the need for social recognition and legitimacy of the loss they experience [70]. Moreover, insecure attachment correlated positively with depression and dementia grief but not with relationship satisfaction. Hence, hypothesis 2.c was partially confirmed. The significant correlation between attachment style and the degree of individual social support $(r(49)=-$ $.393 ; \mathrm{p}<.01$; Adjusted $\mathrm{R}^{2}=.136$ ) is noteworthy, which corresponds with the notion that those with an insecure attachment may have less access to social support resources [38].

The third section of the hypotheses referred to potential differences between research groups on outcome measures. First, considering the independent variables, we observed that spouses of cognitively impaired patients reported higher levels of objective burden and patient's problematic behaviors than the other groups; these findings support the adequacy of these questionnaires to the study goals. Moreover, there was no difference between the groups in terms of attachment style, social support, and physical health measurements. Hence, possible explanations for the following findings due to intervening factors can be partially ruled out.

(3.a) We hypothesized that participants in the group with spouses having cognitive decline will report more difficulties in outcome variables compared to the control group. We observed a significant 
difference between the groups in the expected direction. Therefore, the first had greater levels of dementia grief and depression and lower levels of relationship satisfaction, thus, confirming this hypothesis. In hypothesis 3.b, we expected widowers to report more difficulties on outcome variables in comparison to the control group. Widowers of deceased dementia sufferers indeed reported higher levels of dementia grief and depression than the control group. However, no significant difference was observed between these two groups in terms of relationship satisfaction, and therefore this hypothesis was largely confirmed. These findings provide additional support for the adverse consequences related to caregiving for a loved one suffering from cognitive decline, as has been documented in earlier studies [26, 71-74]. Hypothesis 3.c predicted that widowers would exhibit fewer difficulties on outcome variables in comparison to spouses of cognitively impaired patients. We observed no significant difference between the two groups. Hence, this hypothesis was not confirmed. This finding is concurrent with that reported by Givens et al. [75], according to which there was no significant difference between grief responses in family members of dementia patients before and after the physical loss. It also supports the statement that grief reactions that occur due to the caregiving for a loved one suffering from dementia are not fundamentally different from those occurring after the physical death in terms of their effects on the individual and his/her meaning structures [53].

The fourth hypothesis referred to the moderating effect of attachment style on the association between research groups and outcome variables. We observed no difference between secure and insecure attachment on outcome variables among the control group participants. On the other hand, there was a significant difference between secure and insecure attachment on outcome variables among spouses of cognitively impaired patients and widowers; therefore, insecure participants reported higher levels of dementia grief and depression. Hence, hypothesis 4 was partially confirmed.

The current findings support the argument that one's attachment style may make a significant contribution to promoting emotional adaptation throughout the caregiving role; thus, constituting a factor that promotes mental resilience. That is, those with a secure attachment may be at a lower risk of the negative consequences associated with caregiving for a loved one suffering from cognitive impairment [76], making it a factor that must be considered when formulating a clinical intervention $[39,77]$. These findings are consistent with Adres [78], who concluded that the attachment system is highly relevant in loss and bereavement situations and is more activated due to the inability to reconnect (physically and/or emotionally) with the significant other; thus, leading to the collapse of psychological defenses in facing the reality of loss.

\section{Limitations of the Present Study}

While the current findings support the significance of the grief experience in dementia caregiving, it is important to note the limitations. The modest size of the sample and its characteristics limit the generalizability of the findings, especially concerning cultural diversity, ethnicity, and gender. Therefore, the study needs to be replicated with a larger cohort at multiples sites and with varied demography and cultures. Participants were drawn from a convenience sample of unpaid volunteers, and the extent to which they represent the broader population is not clear. Moreover, the conclusions with regard to the widower's group should be considered highly preliminary. With regard to the 
methodology, the self-report questionnaires were influenced by participants' perspectives, which affect their perception and conveys their experience. The present study is cross-sectional so that while the group differences could be addressed, it was not possible to determine causality between the variables. Lastly, it will be significant to prospectively follow the course of the responses of the participants with repeated measures at suitable intervals.

\section{Conclusions}

The findings of the present study provide preliminary evidence for the utility of the Two-Track Model of Dementia Grief. This model elaborates the theoretical, research, and clinical basis for the consequences of caring and caregiving for a loved one who suffers from cognitive decline prior to and after physical loss giving bifocal attention to the bio-psycho-social aspects of the caregiving role alongside the interpersonal sphere; thus, adequately addressing the limitations of previous models. The TTM-DG is based on a well-established paradigm that has proven to be effective over the past four decades in empirical research and clinical intervention in interpersonal losses and provides reliable measurements that were validated across a variety of languages and cultures $[63,64,79,80]$.

The findings of the current research conform with the transition within the reports on loss and bereavement that emphasizes the importance of the ongoing relationship with the loved one as one of the main foci in the process of coping with the loss [31,32]. Furthermore, these findings may suggest that spouses of people suffering from cognitive decline experience common grief reactions with those experienced by widowers of deceased dementia patients (i.e., content, intensity, and frequency). Finally, the findings highlight factors associated with health and mental resilience and provide a framework that can assist in the process of clinical assessment and intervention with the aim of improving the quality of life of caregivers whose loved one suffers from cognitive decline.

\section{Additional Materials}

The following additional materials are uploaded at the page of this paper.

1. Table S1: Medical diagnosis of patients in the cognitive impairment group (Number of participants).

\section{Author Contributions}

All authors have contributed equally to this paper

\section{Competing Interests}

The authors have declared that no competing interests exist.

\section{References}

1. American Psychiatric Association. Diagnostic and statistical manual of mental disorders (DSM- $\left.5^{\circledR}\right)$. Washington: American Psychiatric Pub; 2013. 
2. Sachdev PS, Blacker D, Blazer DG, Ganguli M, Jeste DV, Paulsen JS, et al. Classifying neurocognitive disorders: The DSM-5 approach. Nat Rev Neurol. 2014; 10: 634-642.

3. Brodsky J SY, Be'er S. The elderly in Israel: Statistical abstract. Jerusalem: Myers-JDC-BrookdaleEshel; 2014.

4. Bowirrat A, Treves TA, Friedland RP, Korczyn AD. Prevalence of Alzheimer's type dementia in an elderly Arab population. Eur J Neurol. 2001; 8: 119-123.

5. Alzheimer's Association. 2019 Alzheimer's disease facts and figures. Alzheimers Dement. 2019; 15: 321-387.

6. Hebert LE, Weuve J, Scherr PA, Evans DA. Alzheimer disease in the United States (2010-2050) estimated using the 2010 census. Neurology. 2013; 80: 1778-1783.

7. Wimo A, Jönsson L, Bond J, Prince $M$, Winblad B, International AD. The worldwide economic impact of dementia 2010. Alzheimers Dement. 2013; 9: 1-11.e3.

8. Fonareva I, Oken BS. Physiological and functional consequences of caregiving for relatives with dementia. Int Psychogeriatr. 2014; 26: 725-747.

9. Pinquart $M$, Sörensen $S$. Associations of stressors and uplifts of caregiving with caregiver burden and depressive mood: A meta-analysis. J Gerontol B Psychol Sci Soc Sci. 2003; 58: P112-P128.

10. Volicer L. Caregiver burden in dementia care: Prevalence and health effects. Curr Psychosis Ther Rep. 2005; 3: 20-25.

11. Peng HL, Lorenz RA, Chang YP. Factors associated with sleep in family caregivers of individuals with dementia. Perspect Psychiatr Care. 2018; 55: 95-102.

12. Roth DL, Sheehan OC, Haley WE, Jenny NS, Cushman M, Walston JD. Is family caregiving associated with inflammation or compromised immunity? A meta-analysis. Gerontologist. 2019; 59: e521e534.

13. Watson B, Tatangelo G, McCabe M. Depression and anxiety among partner and offspring carers of people with dementia: A systematic review. Gerontologist. 2019; 59: e597-e610.

14. Sanders S, Ott CH, Kelber ST, Noonan P. The experience of high levels of grief in caregivers of persons with Alzheimer's disease and related dementia. Death Stud. 2008; 32: 495-523.

15. Blandin K, Pepin R. Dementia grief: A theoretical model of a unique grief experience. Dementia. 2017; 16: 67-78.

16. Karcı YA, Karancı AN. Examination of the psychometric properties of marwit-meuser caregiver grief inventory-short form. Turk J Psychiatry. 2020; 31: 192-200.

17. Liew TM. Applicability of the pre-death grief concept to dementia family caregivers in Asia. Int J Geriatr Psychiatry. 2016; 31: 749-754.

18. Liew TM, Yap P, Luo N, Hia SB, Koh GC, Tai BC. Detecting pre-death grief in family caregivers of persons with dementia: Measurement equivalence of the Mandarin-Chinese version of MarwitMeuser caregiver grief inventory. BMC Geriatr. 2018; 18: 114.

19. Lindauer A, Harvath TA. Pre-death grief in the context of dementia caregiving: A concept analysis. J Adv Nurs. 2014; 70: 2196-2207.

20. Adams KB, Sanders S. Alzheimer's caregiver differences in experience of loss, grief reactions and depressive symptoms across stage of disease: A mixed-method analysis. Dementia. 2004; 3: $195-$ 210. 
21. Cheung DS, Ho KH, Cheung TF, Lam SC, Tse MM. Anticipatory grief of spousal and adult children caregivers of people with dementia. BMC Palliat Care. 2018; 17: 124.

22. Garand L, Lingler JH, Deardorf KE, DeKosky ST, Schulz R, Reynolds III CF, et al. Anticipatory grief in new family caregivers of persons with mild cognitive impairment and dementia. Alzheimer Dis Assoc Disord. 2012; 26: 159-165.

23. Peacock S, Bayly M, Gibson K, Holtslander L, Thompson G, O'Connell M. The bereavement experience of spousal caregivers to persons with dementia: Reclaiming self. Dementia. 2018; 17: 78-95.

24. Chan D, Livingston G, Jones L, Sampson EL. Grief reactions in dementia carers: A systematic review. Int J Geriatr Psychiatry. 2013; 28: 1-17.

25. Corey KL, McCurry MK. When caregiving ends: The experiences of former family caregivers of people with dementia. Gerontologist. 2018; 58: e87-e96.

26. Schulz R, Boerner K, Shear K, Zhang S, Gitlin LN. Predictors of complicated grief among dementia caregivers: A prospective study of bereavement. Am J Geriatr Psychiatry. 2006; 14: 650-658.

27. World Health Organization. International classification of diseases for mortality and morbidity statistics (11th Revision) [Internet]. Geneva: World Health Organization. 2018. Available from: https://icd.who.int/browse11/l-m/en.

28. Lenferink LI, Boelen PA, Smid GE, Paap MC. The importance of harmonising diagnostic criteria sets for pathological grief. Br J Psychiatry. 2019: 215: 1-4.

29. Nielsen MK, Neergaard MA, Jensen AB, Bro F, Guldin MB. Do we need to change our understanding of anticipatory grief in caregivers? A systematic review of caregiver studies during end-of-life caregiving and bereavement. Clin Psychol Rev. 2016; 44: 75-93.

30. Arruda EH, Paun O. Dementia caregiver grief and bereavement: An integrative review. West J Nurs Res. 2017; 39: 825-851.

31. Klass D, Silverman PR, Nickman SL. Continuing bonds: New understandings of grief. New York: Routledge; 1996.

32. Klass D, Steffen EM. Continuing bonds in bereavement: New directions for research and practice. New York: Routledge; 2017.

33. Bowlby J. Attachment and Lxs, Vol. 1. Attachment. New York: Basic Books; 1969.

34. Bowlby J. Attachment and loss: Volume II: Separation, anxiety and anger. In Attachment and Loss: Volume II: Separation, Anxiety and Anger. London: The Hogarth Press and the Institute of PsychoAnalysis; 1973. pp. 1-429.

35. Bowlby J. Attachment and loss: Volume III: Loss, sadness and depression. In Attachment and Loss: Volume III: Loss, Sadness and Depression. London: The Hogarth Press and the Institute of PsychoAnalysis; 1980. pp. 1-462.

36. Cassidy J, Shaver PR. Handbook of attachment, third edition: Theory, research, and clinical applications. New York: Guilford Press; 2016.

37. Burke LA, Neimeyer RA. 11 Prospective risk factors for complicated grief. New York: Routledge; 2013. 
38. Mikulincer M, Shaver PR. An attachment perspective on bereavement. In Handbook of bereavement research and practice: Advances in theory and intervention. Washington: American Psychological Association; 2008. pp. 87-112.

39. Kosminsky PS, Jordan JR. Attachment-informed grief therapy: The clinician's guide to foundations and applications. New York: Routledge; 2016.

40. Monin JK, Schulz R, Kershaw TS. Caregiving spouses' attachment orientations and the physical and psychological health of individuals with Alzheimer's disease. Aging Ment Health. 2013; 17: 508516.

41. Karantzas GC, Romano D, Lee J. Attachment and aged care: A systematic review of current research. Curr Opin Psychol. 2019; 25: 37-46.

42. Rubin SS, Manevich A, Doron II. The Two-Track Model of Dementia Grief (TTM-DG): The theoretical and clinical significance of the continuing bond in sickness and in death. Death Stud. 2019; 43: 117.

43. Rubin S. A two-track model of bereavement: Theory and application in research. Am J Orthopsychiatry. 1981; 51: 101-109.

44. Rubin SS. The Two-Track Model of Bereavement: Overview, retrospect, and prospect. Death Stud. 1999; 23: 681-714.

45. Rubin SS, Malkinson R, Witztum E. Working with the bereaved: Multiple lenses on loss and mourning. New York: Routledge; 2012.

46. Harris DL, Winokuer HR. Principles and practice of grief counseling. 3rd ed. New York: Springer publishing company; 2019.

47. Hoy WG. Bereavement groups and the role of social support: Integrating theory, research, and practice. New York: Routledge; 2016.

48. Neimeyer RA, Holland JM. Bereavement in later life: Theory, assessment, and intervention. In APA handbook of clinical geropsychology, Vol 2: Assessment, treatment, and issues of later life. Washington: American Psychological Association; 2015. pp. 645-666.

49. Pearlman LA, Wortman CB, Feuer CA, Farber $\mathrm{CH}$, Rando TA. Treating traumatic bereavement: $A$ practitioner's guide. New York: Guilford Publications; 2014.

50. Schut MS. The dual process model of coping with bereavement: Rationale and description. Death Stud. 1999; 23: 197-224.

51. Tedeschi RG, Calhoun LG. Helping bereaved parents: A clinician's guide. New York: Routledge; 2004.

52. Worden JW. Grief counseling and grief therapy: A handbook for the mental health practitioner. New York: Springer Publishing Company; 2018.

53. Meuser TM, Marwit SJ. A comprehensive, stage-sensitive model of grief in dementia caregiving. Gerontologist. 2001; 41: 658-670.

54. Noyes BB, Hill RD, Hicken BL, Luptak M, Rupper R, Dailey NK, et al. The role of grief in dementia caregiving. Am J Alzheimers Dis Other Demen. 2010; 25: 9-17.

55. Pearlin LI, Mullan JT, Semple SJ, Skaff MM. Caregiving and the stress process: An overview of concepts and their measures. Gerontologist. 1990; 30: 583-594. 
56. Montgomery RJ, Gonyea JG, Hooyman NR. Caregiving and the experience of subjective and objective burden. Fam Relat. 1985; 34: 19-26.

57. Sherbourne CD, Stewart AL. The MOS social support survey. Soc Sci Med. 1991; 32: 705-714.

58. Wei M, Russell DW, Mallinckrodt B, Vogel DL. The Experiences in Close Relationship Scale (ECR)short form: Reliability, validity, and factor structure. J Pers Assess. 2007; 88: 187-204.

59. Prizant B. Promoting empowering processes for the elderly with disabilities. Haifa: University of Haifa; 2000.

60. Radloff LS. The CED-S scale: A self-report depression scale for research in the general population. Appl Psychol Meas. 1977; 1: 385-401.

61. Kohout FJ, Berkman LF, Evans DA, Cornoni-Huntley J. Two shorter forms of the CES-D depression symptoms index. J Aging Health. 1993; 5: 179-193.

62. Hendrick SS. A generic measure of relationship satisfaction. J Marriage Fam. 1988; 50: 93-98.

63. Rubin SS, Bar Nadav O, Malkinson R, Koren D, Goffer-Shnarch M, Michaeli E. The Two-Track Model of Bereavement Questionnaire (TTBQ): Development and validation of a relational measure. Death Stud. 2009; 33: 305-333.

64. Rubin SS Bar-Nadav O. The Two-Track Model of Bereavement Questionnaire for Complicated Grief (TTBQ-CG31). In: Techniques of Grief Therapy: Assessment and Intervention. New York: Routledge; 2016. pp. 87-98.

65. Georges J, Jansen S, Jackson J, Meyrieux A, Sadowska A, Selmes M. Alzheimer's disease in real lifethe dementia carer's survey. Int J Geriatr Psychiatry. 2008; 23: 546-551.

66. Holley CK, Mast BT. The impact of anticipatory grief on caregiver burden in dementia caregivers. Gerontologist. 2009; 49: 388-396.

67. Meichsner F, O'Connor M, Skritskaya N, Shear MK. Grief before and after bereavement in the elderly: An approach to care. Am J Geriatr Psychiatry. 2020; 28: 560-569.

68. Wawrziczny E, Duprez C, Antoine P. Predictors of caregiver distress among spouses, adult children living with the person with dementia, and adult children not living with the person with dementia. Psychogeriatrics. 2020; 20: 594-601.

69. Moore KJ, Crawley S, Vickerstaff V, Cooper C, King M, Sampson EL. Is preparation for end of life associated with pre-death grief in caregivers of people with dementia? Int Psychogeriatr. 2020; 32: 753-763.

70. Doka KJ. Grief, multiple loss and dementia. Bereave Care. 2010; 29: 15-20.

71. Frank JB. Evidence for grief as the major barrier faced by Alzheimer caregivers: A qualitative analysis. Am J Alzheimers Dis Other Demen. 2008; 22: 516-527.

72. Losada A, Márquez-González M, Vara-García C, Gallego-Alberto L, Romero-Moreno R, Pillemer K. Ambivalence and guilt feelings: Two relevant variables for understanding caregivers' depressive symptomatology. Clin Psychol Psychother. 2018; 25: 59-64.

73. Mausbach BT, Chattillion EA, Roepke SK, Patterson TL, Grant I. A comparison of psychosocial outcomes in elderly Alzheimer caregivers and noncaregivers. Am J Geriatr Psychiatry. 2013; 21: 513.

74. Shah SM, Carey IM, Harris T, DeWilde S, Victor CR, Cook DG. The mental health and mortality impact of death of a partner with dementia. Int J Geriatr Psychiatry. 2016; 31: 929-937. 
75. Givens JL, Prigerson HG, Kiely DK, Shaffer ML, Mitchell SL. Grief among family members of nursing home residents with advanced dementia. Am J Geriatr Psychiatry. 2011; 19: 543-550.

76. Nelis SM, Clare L, Whitaker CJ. Attachment in people with dementia and their caregivers: A systematic review. Dementia. 2014; 13: 747-767.

77. Yehene E, Zaksh Y, Davidian M, Bar-Nadav O, Elyashiv M. Locked-in your heart-shaped box: Familial-role and attachment orientation as predictors of grief in prolonged disorders of consciousness vs. death. Death Stud. 2019; 43: 510-520.

78. Adres I. Attachment and the two-track model of bereavement in parent loss: The contribution of the relationships with spouse, a living child, and "God" to outcome. Unpublished doctoral dissertation). Haifa: University of Haifa; 2010.

79. Ayaz PT, Karanci PA, Aker AT. The reliability and validity study of the Turkish version of two track model of bereavement questionnaire. Turk Psikiyatri Dergisi. 2014; 25: 253.

80. Yasien-Esmael H, Eshel Y, Rubin SS. Bereavement of Israeli Arab Muslim widows: Determinants of adjustment and supporting attributes. Death Stud. 2018; 42: 52-62.

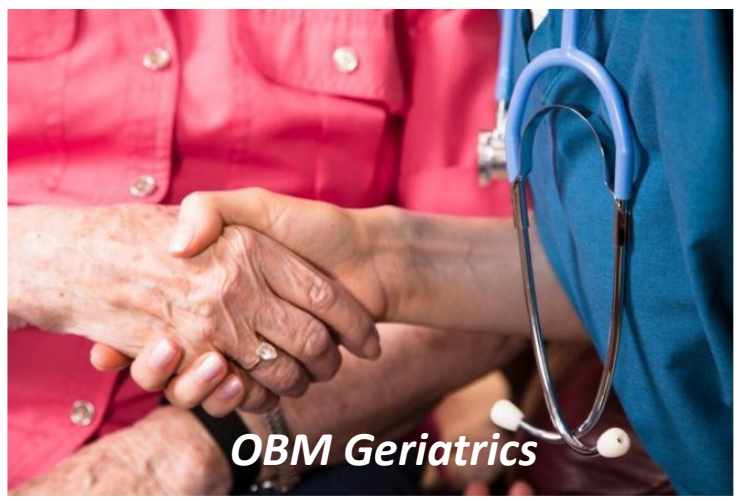

Enjoy OBM Geriatrics by:

1. Submitting a manuscript

2. Joining in volunteer reviewer bank

3. Joining Editorial Board

4. Guest editing a special issue

For more details, please visit:

http://www.lidsen.com/journals/geriatrics 